\title{
A Cinema of sentience: The Simian Gaze in Godfrey Reggio's Visitors
}

Not the final version. This is the accepted version, accepted for publication Feb. 6, 2017 pending future revisions.

Corey Kai Nelson Schultz

University of Southampton

\section{ABSTRACT}

This article analyzes the moving portraits and the gazes of a female lowland gorilla named Triska in the film Visitors (Godfrey Reggio, 2013). By examining the formal qualities of her filmic portrayal and the biological and emotional affects portraits and gazes potentially have on the human viewer, I propose that Triska's gazes create a 'cinema of sentience' that not only represent Triska as a sentient being, but affect an awareness of her sentience and subjectivity. I argue that Reggio's filmic portraits of Triska do not position the viewer as superior to her - our gazes do not conquer or consumer her, and they do not sentimentalize her - rather, her gazes serve to equalize her for the viewer at the level of representation as well as affect, by encouraging the audience to experience a sense of affective empathy for the gorilla and her subjectivity, and to feel the sentience of the non-human Other. In the filmic encounters with Triska, humans become aware of both their humanity and their animality, producing affective moments where biology and philosophy collide - an affective encounter that questions our cognitive philosophical assumptions about what it means to be human and what it means to be animal and simian. 


\section{KEYWORDS}

Affect; gaze; film phenomenology; cinema of sentience; portraits; subjectivity.

\section{Introduction}

The word 'gaze' is defined as 'a steady intent look' (Oxford Dictionary of English 2012). It is not a passive verb; rather, it is an active experience and an activating experience, in that the gaze affects and causes a reaction in the viewer. Triska's gaze has been interpreted as 'the movie's conscience' (Fuller 2014: 48) and as a reminder 'of evolution and the balance between the rational and the bestial aspects of human nature' (Holden 2014: online). Its effects have been described as 'uncomfortable', 'judgemental' (Marsh 2014: 90) and 'guilt-inducing' (Chang 2014: 16), but it has also been argued that her gaze 'commands respect', and produces 'an eerie feeling [...] [that] challenges the viewer' (Keough 2014: online). In this article, I investigate Triska's gazes for their affective qualities by examining my phenomenological experiences of them. I analyse the theories surrounding the human gaze, and compare these theories to how the animal gaze has been understood as functioning, including concepts such as gaze sensitivity and the effects of mirror neurons. I will consider what has been written on the human-animal gaze and the animal-human gaze, as well as their affective qualities in live interactions and screen-based encounters. Using these theories, I will argue that the gorilla's gazes in the film provide affective moments that have the potential to engender an emotional reaction in the viewer. In this way, the formal qualities of her gazes create what I term a 'cinema of sentience'. Sentience, which comes from the Latin sentire, meaning 'to feel' (Collins 2016), emphasizes feeling and affect over philosophical thought. In this cinema of 
sentience, Triska's gazes offer an experience to the viewer that not only represents her as a sentient being, but also emphasizes her subjectivity and self-awareness through affect.

\section{Background to the film}

Godfrey Reggio (b. 1940) is the director of Koyaanisqatsi: Life Out of Balance (1982), Powaqqatsi: Life in Transformation (1988), Anima Mundi (The Soul of the World) (1992) and

Naqoyqatsi: Life as War (2002). These films explore the relationships between humans, animals and the environment: Koyaanisqatsi focuses on the American landscape and the impact on it of society and its technologies; Powaqqatsi on the negative effects of industrialization in the developing world; Naqoyqatsi on the collision between modernity and traditional life; and Anima Mundi records the globe's wildlife. Reggio refers to his work as 'cinematic poetry' (Campbell 2014: online), and his films are famous for recurring motifs such as lush cinematography, time-lapsed photography, aerial and tracking shots, mood music, and humanist and mystical themes (Ivakhiv 2013: 126-127). They have been described as 'wordless, nonlinear film poem(s) urging audiences to contemplate their interaction with the failing planet' (Fuller 2014: 48), but some film critics have also judged them for being 'simplistic, sanctimonious and painfully smug' because they seemingly 'reprimand [their] audience for the ills they've inflected on the world' (Marsh 2014: 90). Although they conflict, these views emphasize the films' striking juxtaposition of the beauty of nature with the destruction of human development, and highlight the differing emotions that can be evoked in the audience when presented with this contrast.

Reggio chose the title Visitors because, for him, the word implies 'to see' and 'to come to see' 
(Anon. 2014), explaining in an interview 'to see is what Visitors is about - to see that which the eye cannot see, to make the invisible visible, to see that which is hidden in plain sight' (MacDonald 2014, original emphasis: online). Focusing on this theme of sight, the film is a conglomeration of long takes. It was filmed in black-and-white because Reggio believed that colour 'contemporizes' film (MacDonald 2014: online), since the presence of colour causes viewers' eyes to 'precognitively go to the different colours to understand the matrix of what's in front of [them]' (Gray 2014: online). As he explained,

when you have color, your eye is scanning the image, it's not your mind, it's your eye, color attracts the eye [...]. Black and white is a more emotive medium, it doesn't portend overt representation. In memory, the less distraction the longer it sticks in the mind. (Kauffman 2014: online)

The visuals in Visitors include images of the moon and the earth from space, the façades of buildings, an abandoned amusement park, a cemetery and the swamps of the Louisiana bayous, but most of the long takes are human portraits. This cinematic trope has appeared in many of Reggio's other films; for example, Anima Mundi (The Soul of the World) includes numerous close-ups of animals' eyes and faces, and the short film Evidence (1995) records children watching television, focussing on their portraits and extreme close-ups of their faces. In Visitors's cinematic portrait gallery, there are faces both old and young. Some are sober portraits that record wrinkles, enlarged pores, and frizzy hair, whilst others look like models in fashion advertisements. In an interview, Reggio explained that the human subjects were 'asked to sit for a portrait' and 'to do what they normally do' (Macaulay 2014: 63). He went on to specify, 
They were not told what to think, what to do. They were just asked to look straight into the camera $[\ldots]$ My own thought $[\ldots]$ is that on a person's face is written who they are. The longer you look at it, the more it reveals itself. (Macaulay 2014: 63)

During my viewing of the film, I was affected by the combination of face, gaze and time, and became entranced with these cinematic portraits and desired to analyse them further. The face and gaze are affective, and portraits are an affective medium; furthermore, the filmic medium's extended temporality provided the opportunity to stare uninhibitedly into another being's eyes. Reggio explained in an interview that he focused on portraiture because 'the most interesting thing that any other human being can look at is the face of another person [...] [it] reveals deeply what's inside of the person' (Campbell 2014: online). In Visitors, he wanted to focus on the gaze, particularly on what he terms the 'reciprocal gaze', explaining 'not only are we gazing at the screen, but in the very overt sense the screen is gazing back at you' (Campbell 2014: online). Elaborating further, he declared 'in this film all of the characters I mentioned are all face-to-face with the audience, in dialogue with the audience through facial expression, eye movement, behaviour and gesture. But their presence is on the screen so long that one gets the chance to stare' (Gray 2014: online). This prolonged moment staring into another's face has the potential to affect the human viewer; or, in Reggio's words, 'trigger(s) something within yourself' (Campbell 2014: online), and 'create a feeling, to watermark the audience, to tattoo them, as it were, with an impression, which is the grand rule of art' (Fuller 2014: 48). Ultimately, it was his desire to create an affective experience, as he asserted, 'this film is not aimed at the cerebellum. It's not aimed at your intellect. It's aimed at your viscera. It's not to tell you a story, it's to give you a story to behold. You fill out what it means' (Anon. 2014: 
online).

Reggio used Errol Morris's Interrotron technique to capture these intimate portraits. In a conventional documentary interview, the camera is placed beside or behind the interviewer, and when the interviewees make eye contact with the interviewer, they are usually looking to the left or to the right, out of the frame and towards the interviewer. In his Interrotron technique, however, Morris places a two-way mirror between the camera and interviewee, and attaches a small video monitor under the lens onto which Morris's own image is displayed. His image is reflected onto the mirror, while the camera has a clear view of the intervieweee's face. Morris addresses the interviewee from this position. When the interviewees seemingly make eye contact with the image of Morris, they are actually looking directly into the camera lens hidden by Morris's virtual projection. Therefore, when the recordings are later screened, the interviewees appear to be looking directly at the viewer. Morris himself discussed the effect of his Interrotron technique, theorizing: 'We're actually looking at each other down the central axis of the lens $[\ldots]$ It's the difference between faux first person and the true first person. There's an added intensity. The Interrotron inaugurates the birth of true first-person cinema' (Gourevitch 1992: online). Shawn Rosenheim has observed that this technique has the potential to provide an affective experience, since it 'clos[es] the dynamic circuit between camera and viewer and intensif[ies] the viewer's cathexis to the screen' (1996: 222). ${ }^{1}$

During Visitor's long takes and their slow unfolding, some of the portrait sitters invite this

\footnotetext{
${ }^{1}$ Cathexis is a term used in psychoanalysis, meaning 'the concentration of mental energy on one particular person, idea, or object' (Oxford Dictionary of English 2012), and is applied here in relation to the investment a viewer makes in the screen image.
} 
experience of a 'first-person' presence and cathexis, while others look through and beyond the viewer, or at something in front of the viewer, even though all of the subjects are filmed via the Interrotron and are therefore looking at screens. Reggio explains that, for him, there are two kinds of portraits: 'from the inside-out', which are composed of people 'consciously sitting for portraits' because they know that their portraits are being taken, and 'from the outside in', which involve people who, although they appear to be watching the viewer, do not have the former's self-consciousness in regards to having their portrait taken (MacDonald 2015: 35152). Similar to Triska's portrait that began the film, one of the film's other long takes is an 'inside out' portrait of a young woman. It lasts approximately one minute and 45 seconds, and she too appears to look at the viewers, contemplating them. In contrast, an 'outside in' portrait of a young man forms part of a group of people that Reggio termed 'The Watchers', who, although they knew that they were being filmed while watching a sports match on the screen, 'as soon as the game came on, it was like a tractor beam - they went right out of their selfconsciousness and into the game itself' (Macaulay 2014: 65). Unlike the previous portraits of Triska and the young woman, the man stares slack-jawed into the camera, apparently unaware of the viewer's presence; he just seems empty. Both types are 'moving portraits' that use time, face and gaze to capture and project the 'living presence' of the portrait subjects (Schultz 2014: 277). Triska, who was also filmed via the Interrotron, appears self-composed, self-conscious, and self-aware, and all three of her gazes are 'inside out', in that she appears to be looking at us, creating the aforementioned affective 'first person' cinema that seeks to address the viewers directly.

\section{People looking at animals; animals looking at people}


Before I consider how Triska's gazes function in the film, in this section I will review what has been written about how people look at animals, and then how animals look at people. In his seminal text 'Why Look at Animals?' (1977), John Berger proposes that animals are 'objects of our ever-extending knowledge. What we know about them is an index of our power, and thus an index of what separates us from them' (1977: 16). As he points out, when zoos were built for humans to look at animals, they generally occurred at the same time as 'animals started to be withdrawn from daily life' (1977: 26). This notion of looking and power is also examined by Anat Pick (2011), who describes the human gaze of animals at the zoo 'as emblems of colonialism', which 'exemplify particular constellations of "powered looking”" (2011: 105). Referring to Laura Mulvey's 'Visual Pleasure and Narrative Cinema' (1975), she argues that 'animals have become, to borrow Laura Mulvey's phrase, "bearers of the human look"' (Pick 2011: 103-104), in that they are to be looked at by humans. Randy Malamud (2012) also cites Mulvey, writing 'the gaze directed at animals in visual culture keenly parallels Mulvey’s formulation of the male gaze. Call it, instead of the male gaze, the human gaze, and replace woman with “animal"” (2012: 74, original emphasis). Referencing Mulvey's statement that in the filmic matrix of gazes, a woman provides the '(passive) raw material for the (active) gaze of man' (1975: 17), Malamud concludes that 'the image of the animal [is] passive raw material for the active gaze of the human', and '[t]he animal is rendered vulnerable, free for the taking, in whatever way the human viewer chooses' (2012: 74). Finally, in 'The Animal that Therefore I Am' (1997), Jacques Derrida writes of his shame and embarrassment at being caught naked before the gaze of his pet cat. The effect of the cat's gaze caused him to consider its affect, declaring 'The animal looks at us, and we are naked before it. Thinking perhaps begins there' (2002: 397). Examining various theories about the animal gaze, he remarks that they fall into two groups; the first is 'by people who have no doubt seen, observed, analyzed, reflected on the 
animal, but who have never been seen seen by the animal [ .. because] they have taken no account of the fact that what they call animal could look at them and address them' (2002: 382, original emphasis). The second, smaller group is by those 'who admit taking upon the themselves the address of an animal that addresses them' (2002: 383). He writes that this address questions human authority over animals, arguing 'animal is a word that men have given themselves the right to give $[\ldots]$ they have given themselves this word, at the same time according themselves $[\ldots]$ the right to the word, the name, the verb, the attribute, to a language of words, in short to the very thing that the others in question would be deprived of' (2002: 400).

In these concepts, animals are to be looked at, named, and conquered and consumed by the gaze. Triska, however, is not only looked at, but appears to return our gaze and make eye contact with the viewer. She halts the conquering and consuming human gaze by looking back - not in fear or in anger or in hesitation, but remains composed, seemingly surveying the viewers as carefully as they are watching her. This impression is amplified by the film's visual style, since many of the portraits' backgrounds were removed in postproduction and replaced with 'blackgrounds' - pure black backgrounds in order to concentrate the viewer's eye on the film-maker's intended object and not its surroundings. In an interview, Reggio explained his decision to excise all Triska's background context, explaining:

If we had shot the gorilla in Uganda or shot the gorilla, as we did, in the Bronx Zoo, then we would be looking at a gorilla. But if you take out the background and put her in the "blackground," then the gorilla is looking at you. It changes the whole dynamic. (Campbell 2014: online) 
To return to Malamud's formulation of gazes and power, if we were watching Triska in a typical zoo enclosure, we would be positioned as superior to her - the powerful human looking down at the imprisoned gorilla behind bars, a subject of human curiosity and amusement, as well as an index of human power. If we were viewing her in her native habitat, our positioning would change to be more anthropological and voyeuristic - perhaps even dangerously so, at least for the cameraperson. Instead, we are presented with a sentient entity who meets our gaze with equanimity.

Triska's self-composure and direct way of addressing the viewer through her gaze can also be viewed as an act of agency. Animal-initiated gazes have been described by Wendy Woodward as 'compel[ling] a response on the part of the human, as it contradicts any assumed superiority of the human over the non-human animal. It is the gaze of a being who actively claims his or her own subjectivity...' (2001: 1). As she explains further,

a cat may look at a queen, then, as the saying goes, but does the queen look back? In this scenario, if the cat's gaze demands it, then the queen has no choice but to return the animal's gaze [...] In doing so she challenges the human-self and animal-other divide, by responding to the cat as a fellow being, rather than as an inferior one. (Woodward 2001: 1)

In this example that echoes Derrida's earlier experience, the cat's look initiates a response from the queen and she looks back. Although the filmic Triska is, of course, not aware of the viewer, her gaze causes us to look back, and thus equalizes Triska with the human viewer at the level of 
representation - her gaze seemingly demands ours, and we stare at her as she stares back unflinchingly. The potential contextual trappings of power (such as the zoo or the jungle) are stripped from the background and we seemingly address each other directly through our exchange of gazes from one living creature to another.

Returning to Berger, he also argues that humans and animals have become estranged and isolated from one another during the modern era due to the growth of capitalism, and this separation has caused animals to gradually disappear from most people's everyday lives. He posits that the expansion of capitalism during the nineteenth century in Europe and North America led to a 'rupture' between humanity and nature, in that previously animals 'were with man at the centre of his world', not only because of our dependence upon them for such things as food and transport, but also because of their spiritual functions: 'animals came from over the horizon. They belonged there and here. Likewise they were mortal and immortal [...]. They were subjected and worshipped, bred and sacrificed' (Berger 1977: 3, 6-7, original emphasis). Berger mourns the loss of the pre- $19^{\text {th }}$ century connection between humanity and animals, which he attributes to Descartes's 'theoretical break' that defined animals as 'soulless' and machine-like, stating 'that look between animal and man, which may have played a crucial role in the development of human society, and with which, in any case, all men had always lived until less than a century ago, has been extinguished' (1977: 11, 28).

Triska's gaze thus offers this lost connection, rekindles the inter-species look and symbolically heals the rupture. We are virtually placed face-to-face with an animal that is seemingly selfaware. Furthermore, due to our similarity with simians - as hominids, we are not-so-distant genetic cousins - our mutual exchanges of looks affect both of us. Researchers have observed 
that both humans and simians are biologically programmed to focus on and 'read' faces; we share the same sensory capabilities and placement of the sense organs, and thus physically have a comparable way of seeing. Moreover, we have similar facial features - a flat face, eyes that face forwards, eyebrows and a nose - which emphasize the eye region (Davidson, et. al. 2014: 8; Emery 2000, cited in Lee, et. al. 2010: 68).

The gaze has the ability to physically affect the viewer. Animal and human sensitivity to the gaze has long been a topic of research, including responses to the gaze such as gaze avoidance, using the gaze as a means of communication, and analysing the gaze as a way to interpret the actions and mental states of others (Davidson, et. al. 2014: 3). We learn through seeing; as several studies on mirror neurons indicate, we not only understand the actions of others through observing them, but we also develop a 'comprehension of other people's intentions, while watching their actions' (Lacoste-Badie and Droulers 2014: 196). This understanding is said to arise from the activity of the brain's mirror neurons, 'which show activity during the execution and also the observation of an action' (Rizzolatti, Fogassi and Gallese 2001; cited in Blair 2005: 700). Mirror neurons are also considered to play a role in the construction of empathy, 'an emotional reaction in an observer to the affective state of another individual' (Blair 2005: 699). Additionally, they have been linked to the development of motor empathy, which is 'the tendency to automatically mimic and synchronize facial expressions, vocalizations, postures, and movements with those of another person' (Hatfield, Cacioppo and Rapson 1994, cited in Blair 2005: 700). Furthermore, both humans and apes are social animals, who utilize 'empathic accuracy', which is the ability to deduce another being's feelings and thoughts in order to respond appropriately to them (Lee et. al. 2010: 68). 
Triska's seemingly self-composed portrait offers the viewer a connection with another sentient being, and her gaze affects us even before we cognitively assess the human-ape biological differences. The affective quality of the ape-human gaze exchange has been theorized by Frans de Waal, who argues:

when the lively, penetrating eyes lock with ours and challenge us to reveal who we are, we know right away that we are not looking at a 'mere' animal, but a creature of considerable intellect with a secure sense of its place in the world. We are meeting a member of the same tailless, flat-chested, long-armed primate family to which we ourselves and only a handful of other species belong. We feel the age-old connection before we can stop to think, as people are wont to do, how different we are. (2013: 1)

de Waal is not the first to make such a claim; as he states, 'many primatologists have experienced a profound change in their attitude towards anthropoid apes after making eye contact with one for the first time' (2013: 1). This change, also referred to as 'the spark across the species barrier' (de Wall 2013:1), is elaborated further by the primatologist and animal rights advocate Karin Saks, who has vividly described one of her encounters with a baboon:

He jumped on to my lap, put his arms around my neck and looked through my eyes to beyond while holding my gaze [...]. An indescribable and undeniable sense of recognition gripped me. I felt exposed [...] with one glance he had caught me unaware, stripped me of self-protective layers and cut through any remaining preconceived notions of primate propaganda that I had been exposed to [...] The self-imposed divide that we have placed between ourselves and other species must surely be an illusion. 
(Saks, quoted in van Riel 2003: 47, referenced in Woodward 2001: 69)

Finally, this sense of recognition and affective bridge over the human-animal divide has been verbalized by the documentary film-maker David Attenborough, who has declared 'there is more meaning and mutual understanding in exchanging a glance with a gorilla than any other animal I know [...]. We see the world the same way that they do' (quoted in Burt 2002: 45). All three of these responses could describe Triska's gazes - the 'connection', the 'spark', the 'sense of recognition' and 'mutual understanding'. This is more than increasing human self-awareness or recognizing animal agency - it is humans recognizing their sameness to animals through the seemingly 'shared' look of sentience during an interspecies gaze encounter.

Triska, though a gorilla, bears a resemblance to the other human portrait subjects in the film, as well as the human viewer. In fact, Reggio chose the lowland gorilla specifically because its face was the most similar to that of a human (Kauffman 2014: online). There is a contrast between Triska's portraits and Reggio's earlier animal portraits in Anima Mundi (1992), in which we only see the animals' eyes and the bridges of their noses. To explore this further, the film starts with a long take of rolling waves on a body of water, and then fades to a close-up of a cougar's eyes that appear to be looking directly at the viewer. During the twenty second long take, it stares at the camera for a few seconds, looks to its left, and then back again, before fading to a shot of clouds racing across the sky. Similarly, a monkey's portrait that appears later in the film lasts for seven seconds - it looks at and around the camera, but seemingly not at the viewer. These portraits do not have the same effects as Triska's. First, the time spent with the viewer is abbreviated, and we do not have the same leisure to gaze at length into each other's eyes. Second, unlike the wider portrait shots of Triska's head, shoulders and chest, these are extreme 
close-ups, and this severe cropping of the face seems to diminish the impact of the animals' gazes. Finally, these earlier sequences also lack Triska's self-consciousness, in that they appear to be observed, and are not returning the gaze. In summary, the affective charge that I experienced with Triska is absent; for instance, while looking at Triska, I automatically search her face for further information, primarily looking at her eyes to which I feel drawn, but in these earlier, truncated gazes the eyes appear disassociated from a face, and the subjects do not appear to be returning my gaze.

Even though the gazes in Visitors are mediated through the screen, this does not seem to lessen their effects, nor does one feel that their 'real' gazes have been replaced with inferior simulacra; rather, the transposition to the screen can enhance the affect of the gazes. According to Steven Shaviro, 'cinema produces real effects in the viewer, rather than merely presenting phantasmic reflections to the viewer', because 'images confront the viewer directly [...]. We respond viscerally to visual forms, before having the leisure to read or interpret them as symbols' (1993: 51, 26, original emphasis). Similarly, Carl Plantinga argues that whether confronted with a person in the flesh or on the screen, in both cases 'the face both communicates information [...] and elicits emotion' (1999: 242). This is because of empathy. Murray Smith describes empathy as 'a type of personal or central imagining' in which we imagine perceiving a situation and 'mentally simulate experiencing it' (2011: 100, original emphasis). In this empathetic imagining, we conjure how another being thinks, feels and 'sees the world' and, through this imagining, develop empathy for them (Smith 2011: 101). In regards to empathy and film, Plantinga describes the close-up of a favoured film character's face as a 'scene of empathy', and argues that such scenes 'communicate emotion' and 'elicit, clarify, and strengthen affective responses - especially empathetic response' in the viewer (Plantinga 1999: 240). These 
responses occur due to 'affective mimicry, facial feedback, and emotional contagion': affective mimicry 'mimics the facial expressions of those with whom we interact'; facial feedback occurs when our faces change in response to the emotions of others; and emotional contagion is “"catching" others emotions' and sharing them, such as laughing together and being sad together (Plantinga 1999: 240-43). These emotional qualities are emphasized over time: as he explains, 'empathy is a process that occurs in time, and emotions take time to catch' (Plantinga 1999: 250).

The portraits in Visitors offer an encounter with other living beings by means of a simulated exchange of gazes experienced over a duration of time, thus allowing empathy the aforementioned 'time to catch'. When the film begins, we are faced with a blank screen. Music composed by Phillip Glass begins to play, and slowly a face emerges - that of Triska. She stares directly at the viewer. Triska's shoulders rise and fall as she breathes; she blinks, momentarily redirects her gaze to the side while moving her head, and then returns her gaze to the viewer. This encounter lasts for approximately 90 seconds. It is not a threatening stare or a frightened look, but rather, is a slow and steady gaze. Our eyes seem to lock - she feels present and appears conscious of our own presence. When I first saw the film, I felt that I was there with her, that I could almost touch her. In response to her looking out of the screen towards me, I felt my body tense and I experienced a mixture of fear, curiosity and wonder; in fact, I was so engrossed in the experience that I even found myself subconsciously matching her breathing rate - the effects of cinematic verisimilitude giving rise to motor empathy and affective mimicry, as they unfolded over time during her long take. Through the cinematic gazes, we are positioned in a way that the vast majority of us will never be - face-to-face with a gorilla. Although we are obviously not in close physical proximity to Triska and our sensual contact 
with her is limited - we do not feel her breath, smell her body odour, our allergies do not react to her fur, and we do not feel the heat from her body - the gaze still affects us and makes us feel that she is there. Finally, Triska's is not a friendly stare; I did not see a sentimental or adorable gorilla in front of me, but a composed and self-aware being. Yet, we are 'safe' - we cannot be threatened by Triska, nor she by us, but we are being held by her stare, immersed in the experience until the image finally fades to darkness.

Hers is an 'inside out' portrait that projects out into the world, offering a possible connection to the receptive, empathetic viewer. This scene thus provides us a rare experience to spend time (virtually) with Triska, and absorb ourselves in the act of looking. As Catherine Elwes argues in her discussion of Andy Warhol's 'Screen Tests' (1964-1966), these long take film portraits presents to the viewer "the opportunity to "stay with" another person, to register the lineaments of a face, and, over time, to catch the fleeting expressions that play across human features as the interior life momentarily breaks the surface' (2015: 123). This shared moment of 'staying with' Triska not only allows us to examine her face and follow her expressions, it also offers us that aforementioned 'connection', 'spark', 'recognition' and 'mutual understanding' experienced by the primatologists, and one that recreates the 'lost connection' mourned by Berger.

The second section featuring Triska occurs half way through the film. She reappears at the end of a sequence of portraits of people, thus being positioned as equal and not inferior to the human portrait subjects in terms of the language of the film. During the start of this scene, the camera pans right, and slowly moves past the human portraits. As Triska enters the frame, she is looking to screen left, seemingly at those who came before her, taking her place as just another member of this cinematic portrait gallery, and it seems natural for her to be there, 
alongside her distant human cousins. When her head reaches the centre of the frame, however, she turns to look directly at the viewer and breaks the fourth wall. Just as our gazes meet, the camera stops its motion, and she spends about 30 seconds staring directly at us. She breathes and blinks, all the while holding our gaze. This begins her self-conscious 'inside out' moving portrait. We feel that we are again sharing a look, each looking back at the other within an assumed consciousness of the other's presence. As it does in the first sequence featuring Triska, time seems prolonged in this encounter - a duration of 'real time' that contrasts with the other portraits and long takes in the film that appear to radically manipulate time by slowing it down or speeding it up. For example, when some of the human subjects blink, they are rendered in prolonged slow motion, while other scenes are speeded up using time-lapse photography clouds race by, the sun quickly rises and sets and shadows grow and disappear, all in takes lasting several seconds. Such manipulations of time remove the viewer from the onscreen time frame. Triska's episodes, however, are in real time and emphasize the 'present-ness' of a parallel space and time unfolding on screen, which creates a feeling of shared time. Thus, she is not distantly observed by viewers located outside the film's temporality, but her living presence is encountered within it.

Before Triska's final portrait, we see a blue earth rising from the moonscape (the only use of colour in the film). Earth fades away as Triska's face fades in. She looks at the audience. The camera slowly zooms out, and we see that she is depicted on a movie screen looking out while an audience is gazing at her on the screen before them. However, she is not looking at them but at us, since her gaze passes above their heads and is directed into our eyes. This scene ends with Triska on the movie screen becoming increasingly brighter until she dissolves into a white light that begins to spill out of the screen and slowly encompasses the audience; finally, the entire 
screen fades to white as the music swells. The film began with a fade from black, so the fade to white is not only a device that helps to bookend the beginning and ending of the film, but it also gives a feeling of expansion, as if the viewer has been absorbed into the ever-expanding brightness and has merged with it and thus with Triska.

In these three scenes, we are invited to recognize Triska's state of sentience - not only to realize her subjectivity intellectually, but also to feel it through the affect of her gazes. As I outlined in my introduction, sentience relates to feeling. Whilst watching the film's portraits, the viewer sees, feels and is affected by the subjects' gazes framed in a series of high-definition, realistic portraits. They create an intimate experience, in that we appear to stare into another being's eyes. Unlike the conventional configuration of human-to-animal gazing I have referenced, in Visitors we do not feel empowered to experience ourselves as superior to her, our gazes do not conquer or consumer her, and we do not sentimentalize her; rather, we acknowledge her 'being' and sentience. Thus, her gazes serve to equalize her for the viewer at the level of representation, but they do not equalize her by anthropomorphizing her - that is to say, we do not see her as human, but instead perceive her as an independent entity through the creation of an empathetic cinematic experience via the gaze encounters offered in this cinema of sentience.

In The Open: Man and Animal, Giorgio Agamben analyses Carl Linnaus's concept found in Systema Natura (1735) that 'man has no specific identity other than the ability to recognize himself $[\ldots]$ man is the being which recognizes itself as such, that man is the animal that must recognize itself as human to be human' (2004: 26, original emphasis). The portraits in Visitors offer the human viewers the opportunity to recognize themselves in the subjects onscreen; in the filmic encounters with Triska, however, humans become aware of both their humanity and 
their animality, producing affective moments where biology and philosophy collide - an affective encounter that challenges our cognitive philosophical assumptions about the animal Other. However, this also goes the other way, in that Triska is not only looked at, she appears to look back, as if recognizing the human as also similar to herself. This puts the viewers in the position of not only perceiving the human in the ape but also ourselves becoming the object of the ape's apparent recognition of her similarity with the human - the 'spark' of sentience. Although Triska of course cannot see us, her gaze makes us feel like she can; thus, this seemingly 'mutual' recognition from the perspective of the human viewer offers affective moments of 'shared' sentience, from which we can formulate a notion of inter-species equality and self-awareness.

To conclude, these scenes with Triska are not ethnographic recordings of an animal in her natural environment; in their stripped-back encounter with Triska, they challenges how we

see the animal Other and how we define the borders between the species. As Béla Balázs once argued, 'good close-ups are lyrical; it is the heart, not the eye, that has perceived them' (1953: 212). Sentience and empathy allow us to 'see through the heart', through emotion rather than solely through cognition. With her gaze, Triska has been individuated not only as an ape, but as a sentient being and this moves us beyond the cognitive-based ethics associated with the 'Other' and instead invites us to feel the agency of the Other. Thus, the film creates a cinema of sentience enabling us to share some time with a gorilla named Triska, and we, as audience, have the opportunity to experience a sense of affective empathy for her and her subjectivity. 


\section{REFERENCES}

Agamben, G., (2004), The Open: Man and Animal, Stanford: Stanford University Press.

Anonymous, (2014), 'Godfrey Reggio's Visitors a wordless portrait of modern life', $C B C$ News, 3 February. Online: http://www.cbc.ca/news/arts/godfrey-reggio-s-visitors-a-wordlessportrait-of-modern-life-1.2521734. Accessed 1 January 2015.

Balázs, B. ([1953] 1971), 'Theory of the film', in D. Talbot (ed.), Film: An Anthology, Berkeley: University of California Press, pp. 201-15.

Berger, J. (1980), About Looking, London: Bloomsbury.

Blair, R.J.R. (2005), 'Responding to the emotions of others: dissociating forms of empathy through the study of typical and psychiatric populations', Consciousness and Cognition, 14, pp. 698-718.

Burt, J. (2002), Animals in Film, London: Reaktion.

Campbell, C. (2014), 'Godfrey Reggio on "Visitors," making a special effects-driven documentary and slow motion versus time-lapse', Nonfics, 16 June. Online: http://nonfics.com/godfrey-reggio-visitors-special-effects-driven-documentary-slow-motionversus-time-lapse/. Accessed 30 March 2016.

Chang, C. (2014), 'Beautiful relationships: the Reggio-Glass Qatsi trilogy - part four?', Film Comment, January-February, p. 16.

Collins English to Italian Dictionary (2016). Online: http://www.collinsdictionary.com/dictionary/english-italian. Accessed 30 March 2016.

Davidson, G.L., Butler, S., Fernández-Juricic, E., Thornton, A. and Clayton, N.S. (2014), 'Gaze sensitivity: function and mechanisms from sensory and cognitive perspectives', Animal Behaviour, no. 87, pp. 3-15. 
de Waal, F. (2013), The Bonobo and the Atheist: In Search of Humanism Among the Primates, New York: W.W. Norton.

Derrida, J. (2002), 'The animal that therefore I am (more to follow)', D. Wills (trans.), Critical Enquiry 28:2, pp. 369-418.

Elwes, C. (2015), Installation and the Moving Image, London: Wallflower Press.

Emery, N.J. (2000), 'The eyes have it: The neuroethology, function and evolution of social gaze', Neuroscience and Biobehavioral Reviews, no. 24, pp. 581-604.

Fuller, G. (2014), 'Storm warning: A Q \& A with Godfrey Reggio, whose latest documentary forecasts dystopia', Modern Painters, 26:1, pp. 48-49.

Gourevitch, P. (1992), 'Interviewing the universe', The New York Times Magazine, 9 August. Online: http://www.errolmorris.com/content/profile/bhot_gourevitch.html. Accessed 30 May 2016.

Gray, D. (2014), 'Techno/logic: interview with Godfrey Reggio', Totally Dublin. Online: http://totallydublin.ie/film/technologic-interview-godfrey-reggio/. Accessed 15 June 2016.

Hatfield, E., Cacioppo, J.T. and Rapson, R. (1994), Emotional Contagion, New York: Cambridge University Press.

Holden, S. (2014), 'Staring at you, staring at me', New York Times, 23 January. Online: http://www.nytimes.com/2014/01/24/movies/godfrey-reggios-visitors-is-a-slow-parade-offaces.html 1/3. Accessed 1 February 2015.

Ivakhiv, A.J. (2013), Ecologies of the Moving Image: Cinema, Affect, Nature, Waterloo: Wilfred Laurier Press. 
Kauffman, J. (2014), “Visitors” director Godfrey Reggio: Exclusive interview', Blu-ray.com, 30 May. Online: http://www.blu-ray.com/news/?id=14112. Accessed 1 January 2015.

Keough, P. (2014), 'In "Visitors", the face of an ape, the plight of a planet', Boston.com, 13 March. Online: http://archive.boston.com/ae/movies/2014/03/13/visitors-the-face-ape-theplight-planet/1AUmStvI8yGIyY9GmWe8aP/story.html. Accessed 19 September 2016.

Lacoste-Badie, S. and Droulers, O. (2014), 'Advertising memory: The power of mirror neurons', Journal of Neuroscience, Psychology, and Economics, 7:4, pp. 195-202.

Lee, S.A. Guajardo, N.R., Short, S.D., and King, W. (2010), 'Individual differences in ocular level empathic accuracy ability: The predictive power of fantasy empathy', Personality and Individual Differences, no. 49, pp. 68-71.

Macaulay, S. (2014), 'Observe and report', Filmmaker, 22:2, pp. 62-69.

MacDonald, S. (2014), 'Interview: Godfrey Reggio', Film Comment, 5 February. Online: http://www.filmcomment.com/blog/interview-godfrey-reggio/. Accessed 30 March 2016.

MacDonald, S. (2015), Avant-doc: Intersections of Documentary and Avant-garde Cinema, Oxford: Oxford University Press.

Malamud, R. (2012), An Introduction to Animals and Visual Culture, Houndmills: Palgrave Macmillan.

Marsh, C. (2014), 'Visitors', Sight \& Sound, April, pp. 90-91.

Mulvey, L. (1975), 'Visual pleasure and narrative cinema', Screen, 16:3, pp. 6-18.

Oxford Dictionary of English (2012) ( $3^{\text {rd }}$ ed.), Oxford: Oxford University Press [app].

Pick, A., (2011), Creaturely Poetics: Animality and Vulnerability in Literature and Film, New 
York: Columbia University Press.

Plantinga, C. (1999), 'The scene of empathy and the human face on film', in C. Plantinga and G.M. Smith, (eds.), Passionate Views: Film, Cognition, and Emotion, Baltimore: The Johns Hopkins University Press, pp. 239-255.

Rizzolatti, G., Fogassi, L. and Gallese, V. (2001), 'Neurophysiological mechanisms underlying the understanding and imitation of action', Nature Reviews of Neuroscience, no. 2, pp. 661-70.

Rosenheim, S. (1996), 'Interrotroning history: Errol Morris and the documentary of the future', in V. Sobchack (ed.), The Persistence of History: Cinema, Television, and the Modern Event, New York: Routledge, pp. 219-34.

Schultz, C. (2014), 'Moving portraits: portraits in performance in 24 City', Screen, 55:2, pp. 276-87.

Shaviro, S. (1993), The Cinematic Body, Minneapolis: The University of Minnesota Press.

Smith, M. (2011), 'Empathy, expansionism, and the extended mind', in A. Coplan and P. Goldie (eds.), Empathy: Philosophical and Psychological Perspectives, Oxford: Oxford University Press, pp. 99-117.

van Riel, F. (2003), Life with Darwin and other Baboons, Johannesburg: Penguin.

Woodward, W. (2001), The Animal Gaze: Animal Subjectivities in Southern African Narratives, Johannesburg: Wits University Press.

\section{ACKNOWLEDGEMENTS}

This project was funded by a University of Southampton Small Awards Grant (2015). An earlier version of this article was presented at the Screening Animals and the Inhuman: 25th 
Annual Screen Studies Conference (2015).

\section{CONTRIBUTOR DETAILS}

Corey Kai Nelson Schultz is a lecturer (assistant professor) in Film at the University of Southampton. He received his $\mathrm{PhD}$ from Goldsmiths, University of London, and his research areas are Chinese visual culture, film phenomenology and aesthetics.

Email: c.schultz@soton.ac.uk; chns@,berkeley.edu. 